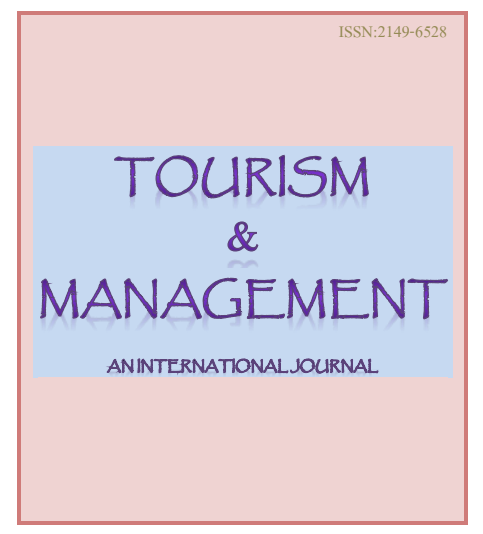

Journal of Tourism\&Management Research ISSN: 2149-6528

2018 Vol. 3, Issue.3

\title{
The Effect Social Media on the Development of Sport Marketing Strategy: The Case Study of Football Clubs in Northern Iraq
}

\begin{abstract}
This study aims to examine the effectiveness of social media for the football sport club's marketing strategy in Northern Iraq. The data were collected by semi-structured interviews and analyzed using content analysis. Sampling strategy used in this study is maximum variation sampling. The outcomes of this study reveal that developing the social media tools are significant for the football sport clubs to thrive the sports marketing strategy and increase their relationships with the fans in a professional way. The football sport clubs need to adopt the social media as a strong channel for developing the sports marketing strategy and grasp the fans as a key product. They should have the ability to use different types of social media tools. Through this development football clubs will be able to make important progress in the advertisement, expand the number of fans, develop their marketing strategies, and improve their financial ability.
\end{abstract}

Keywords: Social media platform, Traditional media, Sports marketing strategy, Football sport clubs, Northern Iraq.

JEL Classifications: L83, M31, M37.

Submitted: 10/08/2018; Accepted:16/11/2018

Azhi Khalil Bapir. Research Assistant. Institute of Graduate Studies and Research, Department of Business Administration, Cyprus International University, North Cyprus.

Email: shazsport@yahoo.com

Hale Ozgit, Associate Professsor. (Corresponding Author). School of Tourism and Hotel

Management, Cyprus International University, 99258 Haspolat, North Cyprus, Mersin 10 Turkey

Email: hozgit@ciu.edu.tr

\section{Introduction}

Global competitive conditions lead companies to focus more on their marketing strategies. Furthermore, a real competitive advantage gives rise to the companies to satisfy the customer needs more efficiently than their competitors (Thompson, 1997). The competitive advantage always consists of two methods: (i) it surpasses those of different services or items in the specific business, and (ii) the cost advantage is the company's ability to provide the similar 
benefits as competitors at a lower cost (Eric et. al., 2013). Through the understanding of these ideas, the marketers and the marketing professionals could implement a more capable and resourceful marketing strategy efforts (Eric et. al., 2013). It is crucial to understand the importance of a marketing strategy as it boosts companies to ask the essential questions about what they are striving to reach their marketing objectives and how they will finish it (Jackson, 2013). Besides, the process of improving marketing strategy has a fundamental value in encouraging important issues and it assists companies and events to concentrate on their struggles (Jackson, 2013). The aim of producing a right marketing strategy is to work out about how the best practices of the allocated organizational resources will be used. Therefore, a marketing strategy is about meeting an event's capability and skills in the environment (Crowther, 2010).

Nowadays there is a developmental change in digital marketing (DM), especially to sell and advertise a product or services (Sinha, 2007). In addition, the introduction of the latest communication technology has built up various openings and difficulties for traditional media (TM) (Garrison, 2001). In fact, the development of online networking and the web has represented a test to conventional media, particularly the printed newspaper (Domingo and Heinonen, 2008), even more, the social media (SM) have also made an influence on the method of the newspapers to broadcast their news (Garrison, 2001).

The SM website makes communication and relationship opportunities, which gives the possibility to access the immediate contact with the target audience (Schwarz, 2008), comparing to other TM forms of media like newspaper, radio or TV. Changing the one-way conversation to a several-way, one which could be established by SM is an important difference with the TM (Schwarz, 2008). By increasing the importance of the internet, the balance is changing from TM towards a variety of online communication forms (Schwarz, 2008). Alterations in marketing communications about manufacturing and in services companies also lead to changes in sports marketing as well. Sport teams of marketing hints all marketing relevant activities that happen in the sports organization or administration of professional sport clubs (Parent and Smith-Swun, 2013), that include: the whole communication with the fans and other shareholders that act as the customers, the marketer has to have the ability to assure that the relevant information is presented to every sort of customers, particularly the fans (Chadwick et. al., 2015).

Today, using the internet is so crucial for the fans or even for those who want to search for something (Kendall et. al., 2010). Social networks are now playing an important role in many of the companies with the desire of employing the best strategy in their business (Askool and Nakata, 2011). The social media platform (SMP) has provided their users with opens unique areas and various features for discussion and interaction (Azizi and Tambuan, 2018). The different usages of the SM are so effective in a digital sport's club marketing strategy method, when the fans are trying to connect to their favourite clubs by using the SM (Jarvie, 2013), particularly the Facebook is the favoured SM to mobilize and occupy with an enormous fan base (Tang and Cooper, 2017). The development of social media tools (SMTs) has installed a novel dynamic in sports marketing, then the SM has created a leadership for the football clubs to engage fans above all Facebook tool. Northern Iraq has recently facilitated a technological development in many aspects. SM usage (e.g. Facebook, Instagram, Twitter, etc.) is increasing steadily in the sports industry and among the people in Northern Iraq. Many young people in Northern Iraq frequently practice the social media network (SMN) as a mean to link to press, companies, managers, and businesses (Invest in the group, 2013). Invest in the group (2013) reported that almost fifty percent of the people in Northern Iraq use an SM application at least once a week, and seventy-two percent of Iraqi Facebook users are between 18-34 years old. Facebook is visited the most famous website in Northern Iraq; supported via YouTube, Yahoo, and Google. However it is important to emphasize on the effective usage of the social media for the football sport clubs as a marketing tool in Northern Iraq. This can 
lead football sport clubs to understand how to increase their relationships with their fans through a well-developed marketing strategy.

The purpose of this research was to understand the effectiveness of social media for the football sport clubs marketing strategies. So this study, planned to know about the method by which the football clubs can increase their relationships with their fans through an effective use of the SM, when there is a lack of football clubs' understanding about the competence of SMP in Northern Iraq to engage fans which will support them to develop their marketing strategies and improve their financial ability. The main research question of the study was asking the role of social media in the development of marketing activities for the football sport clubs. Besides, it football sport clubs were asked to analyze whether they can consider the social media as a strong channel for developing their sports marketing strategies and improve their financial ability.

\section{Literature review}

\subsection{Traditional Media in the Football sport Clubs}

Before the advent of the new media and the other media applications, the dissemination of games content was customarily overseen and controlled by journalists, broadcasters, and other followers of TM (Hutchins and Rowe, 2012). The TM makes people think about when they can speak regarding advertising, holding festivals and sharing news, such as cable television, radio, broadcast television, Banner Ads, print advertising, Door-to-Door sales, cold calling and newspaper (Ward, 2003). The sports and the media are classic outcomes and both have developed rapidly and extensively as a major global industry (Saini, 2015). Each of them has a local and global scope of operation and has the structures and practices to reflect this, and the industries of sport and media are interconnected to each other (Saini, 2015). In activities, football tournaments have privileged ways and means of connection for business desiring to improve their image, brand recognition and novel market (Manzenreiter, 2004).

Likewise, the TM had been the best ways for making relationship with football sport fans and they began with their local newspapers providing limited opportunities for sport fans to share their views by a letter page (Haynes, 1995). Today, the TM are not playing an indispensable role in the football sport clubs because of the development of SMP, the TM became an old and uninteresting way for the sport fans to check the information or news about the football club, and, when the fans want to look up for specific information on the TM, it will take a long time. Showing more football matches on TV resulted in more advertising income that has become a phenomenon with media and sports (Gluck and Rocam, 2008), so that during this time, advertising on television has been decreased as audiences were spread out over different channels.

\subsection{Social Media Platforms and Sports Marketing Strategy}

There are two different streams of sports marketing strategy, which are marketed 'through 'sport and marketing strategy 'of 'the sport (Smith, 2008:2). Sport has embedded in the sociocultural framework of a lot of states and can build and maintain deeply recognized and invested fans across a wide range of demographic groups (Westberg et. al., 2018). Morgan and Summers (2005:5), define the sports marketing as "the process of designing and implementing activities for the pricing, distribution and production, as well as sharing of a sport industry product to satisfy the desires of customers and to reach the company's goals". Sports-marketing has formerly seen as an influential channel to increase sales and support in the commercial activities of individuals and sport clubs (Manoli, 2017).

When we want to ask what the SM is and most of the people respond, it is the internet (Charness and Holley, 2004), because the SM is a strong marketing channel due to revealing a lot of important features such as empowering web users to organize specify all the different information by the best method (Musser, 2007). Whatever, the internet is not considered as 
the SM, it is the technology that permits people to communicate through the new medium. The SM is currently running an essential role in a digital sport club's marketing strategy and delivering the best marketing strategy opportunities for the football sport clubs also it is an important way through which fans have the skills to engage with a sport (Williams and Chinn, 2010). The SMPs are to be found as an emergent of communication that can entice the sport fans of the incredible way, as well as the appearance of SM, particularly those with a picturesharing feature, has influenced the design of dissemination, therefore becoming a modern space for publishing idealized attractiveness (Azizi and Tambuan, 2018).

The SMPs and sports marketing strategy have been going steady for a few years now, also their relationship is about to be driven to the close level (White et. al., 2017), and prominent social media stations are where consumers now exist, besides growing a brand community online is an indispensable section of every marketing strategy (Goodyear et. al., 2018), furthermore the SMPs have granted a new framework of the communication method, it is recognized as a vital part of interactive marketing communications, then consumers practice the SM stations to interact with each other or companies, therefore many marketers establish the social media into their marketing strategy (White et. al., 2017).

The prevalence and attractiveness of the SM technology have built supremacy to the sport marketers to make innovation and communicate with fans (Shilbury et. al., 2009), and then it makes the marketing strategy of the football sport clubs to develop, and especially it improves the sponsors situation, public relations, and the sale strategy (price) club (Shilbury et. al., 2009). SM does not need a strong financial investment, and the pretty low cost is surely a benefit of developing a SM site as a marketing communication tool, it provides the opportunity for the football team to reach a huge income from these developments (Michaelidou et. al., 2011). The SM progress has released a novel world of commercial chances in the sports marketing strategy and other business parts, also increased the need for the matching agreements to be prepared until to preserve and present the new media rights (Blackshaw, 2012).

\subsection{The Key Social Media Tools in the Football Sport Clubs}

The SM as an advertising tool is considered as the most prevalent way of communication (Rothschild, 2011). Concentrating on the SMTs are so effective way for the professional football clubs and players to reach a high-quality connection with extra monitoring during the announcement of sport news and swelling their survival running (Sanderson and Kassing, 2011).

The SMTs can enlarge the purchasing profits of the football club and hold the game appearance, term ticket owners (Neale et. al., 2003), similarly the power of SM tools has enlarged profits from ticket sales (Kim et. al., 2011). The ticket selling had an influenced on the development of the football sport leagues, attendance at matches makes a good effect on the teams and leagues and it can improve the leagues in the future. Facebook as being the most effective instrument for assembling a group of loyal fans (Pronschinske and Walker, 2012), and a Facebook page is a beneficial way to attract the football fans and in this way they can give some more information to each other and enjoy supporting their team, besides the Facebook channel improves the two-way dialogues with the club, which has the robust competence to offer giant profitable and then evolve their marketing strategy (Mangold and Faulds, 2009). Currently, Facebook has developed into the world's highest community of sports fans through giving a platform for 650 million people to join with sports pages, and also it is true that the Facebook has become the world's greatest stadium (Jalonen, 2017). People also have the capability to share videos and photos through Instagram. Everybody like Facebook and Twitter can open accounts to prove their pictures in a prominent way (Gadiraju, 2016). According to Berthon et. al. (2012), LinkedIn is the most famous social media network for business networking and communications. It is actually valuable for making new 
relationships, designing an official profile and applying for the jobs in this technological commercial world. As well as, Myspace had popularity in the US. There are some companies such as Puma, Nike, and Adidas were quickly connected with the promotions that comprised online channels, print ads, and TV sports, especially Nike associates with Google to create the first SM website for the worldwide soccer followers (Newman et. al., 2013).

YouTube could be used to give modern information, then through YouTube services, people can show videos, ideas, and facilities clearly (Saw et. al., 2013). Moreover, YouTube serves as an example of an electronic component which the football sport clubs should use to construct a virtual participation and implement it efficiently (Pritchard \& Stinson, 2014). On the other hand, the fans, players and sport clubs have been a fast growth in the implementation of the micro-blogging podium Twitter (Hutchins, 2011). Sports leagues might get the benefit of Twitter's capabilities also tasks through the dyed-in-the-wool fans who are aware of football club proceedings and rely on its products (Witkemper et. al., 2012). There are some of the football clubs which have used the SM tools and they have a lot of fans on Facebook websites, such as Bayern Munich, which has the biggest team membership in the German Bundesliga of 162187 (Bayern Munich, 2011) and Manchester United has 333 million followers around the world (Anderson, 2008; Cass, 2007), consists of 193 million in Asia also 95 million as Facebook followers.

The Snapchat application is a brilliant tool in which every video and photo just last for a short time before they vanish forever, it is an ephemeral app in nature, nevertheless people can take a screenshot of every snaps that they do to save them in the picture form (Joseph et. al., 2015), and Viber media were obtained by the Japanese multinational company and it had 800 million registered users in December 2016 (Mance, 2014).

\section{Methodology}

\subsection{Research Design}

This study employed a qualitative approach. The aim of using the qualitative approach is to gather information from the participants according to their ideas about the football sport clubs, sports management and the existing structure of the sector. The qualitative research technique has been determined to grow awareness and gaining the possible understanding of the using SMP into the football sport clubs in Northern Iraq till expand their relationships with fans which will make a progressing chance for the marketing strategy. The semistructured interview is being used in order to understand participants' perceptions of the effectiveness of SM in developing football clubs marketing strategies.

\subsection{Sampling and Data Collection}

The maximum variation sampling method has been used as a type of the purposive sampling strategy. By using this sampling strategy each case, based on the selected sampling, would be identified more detailed (Yildirim and Şimsek 2006: 107). In this regard, twelve popular presidents of the football sport clubs have been chosen to face to face interview in different league ranks from Northern Iraq provinces (Erbil, Sulaymaniyah, Duhok and Kirkuk) (See Table. 1). Each semi-structured interview form adopts a number of questions by which the best understanding of the problem and purpose of this research can be achieved and make benefit for the research questions.

The primary data for this study were collected through semi-structured interviews which were conducted with twelve presidents of the football sport clubs from Northern Iraq. The semi-structured interviews have been broadly used in the social media platforms context, and delivered flexibility to change prior and during the interview to become familiar with the flow of the discussion (Bryman and Bell, 2011). Afterwards, in the light of the aim of this research, interview forms residing of fourteen questions have been prepared. All presidents of the football sport clubs were communicated earlier in the interview and were informed regarding 
its content. On August 9th, 2017 took place the first interview and the last one on September 14th, 2017, every interview took place at the president sport clubs headquarters in four cities (Erbil, Duhok, Kirkuk, and Sulaymaniyah) and they were recorded with the consent of the interviewees. Some of the interview questions which guided our study were as follows:

1. What is your current marketing strategy for your football club? Or how do you advertise for your sports events?

2. What is your idea about the social media power to develop the marketing activities of the football sport clubs?

3. What are the most important types of social media tools you see them as the most useful ones for the football sport clubs to increase their relationships with fans?

Regarding to research questions two categories were defined to cope with different facets of the study, namely: the social media as a strong channel marketing strategy, and profitability via the social media to engage fans.

Table 1: Research Participants.

\begin{tabular}{|l|l|l|}
\hline Football Sport Club & City & $\begin{array}{l}\text { Number Of } \\
\text { Participants }\end{array}$ \\
\hline Peshkawt football club & Erbil & 1 \\
\hline Ararat football club & Erbil & 1 \\
\hline Aso football club & Erbil & 1 \\
\hline Brusk football club & Erbil & 1 \\
\hline Erbil football club & Erbil & 1 \\
\hline Peshawa football club & Kirkuk & 1 \\
\hline $\begin{array}{l}\text { Sulaymaniyah football } \\
\text { club }\end{array}$ & Sulaymaniyah & 1 \\
\hline Ashty football club & Sulaymaniyah & 1 \\
\hline Sanhareb football club & Duhok & 1 \\
\hline Gara football club & Duhok & 1 \\
\hline Duhok football club & Duhok & 1 \\
\hline Zakho football club & Duhok & 1 \\
\hline
\end{tabular}

\subsection{Data Analysis}

Content analysis method was used in the analysis of the data obtained in the research and in the processing of the data. Through this method, direct quotations about the discourses of the individuals participating in the research were made and the data were transferred to the reader with a descriptive approach. Afterwards the text is divided into meaning units and then data were condensed (Graneheim and Lundman, 2004). In the analysis of the data, the participants are not mentioned with their real names and they are defined with abbreviations. Presidents of the football sports clubs are indicated by the abbreviations of P1, P2 and etc.

\section{Results}

\subsection{Social Media as a Strong Channel Marketing Strategy}

Development of social media has moved all businesses to a new area, and Azizi and Tambuan (2018), explain that SMPs are to be found as an emergent of communication that can entice the fans of the incredible way, as well as, SM tools have provided their users with opens unique areas and various features for discussion and interaction, especially now customers 
can talk with hundreds or thousands of other people (Azizi and Tambuan, 2018). This is true for the football clubs as it is also mentioned by P1 and P8 as follows:

"The SM a is a strong channel for developing the sports marketing, particularly in the Northern Iraq people adore the SM tools."

Also, P3 confirmed the same expression who said:

"Yes, we can see the social media as a strong channel for developing the sports marketing, because the SM doesn't need so much time and cost."

Similarly, P6 and P11 had the same understanding as they mentioned:

"Yes, if we see the SM as a strong channel for developing the sports marketing, it will be a good opportunity for the club, but before they need to learn about using the SM tools entirely. Many clubs have recently been practicing the SM and they can develop their marketing through this platform."

Concerning Musser's study (2007), SM is a strong marketing channel because of revealing a lot of important features such as empowering web users to organize specify all the different information by the best method. A crucial example, The International Olympic Committee (IOC) recorded more than five billion SM impressions at the Rio Olympics in 2016, and presently counts fifty million followers across all its SM stations (Tang and Cooper, 2017), as P10 stated as follows:

"The SM is a strong channel for developing the sports marketing; particularly in Northern Iraq, the SM has many users. Moreover, many sport fans like to see the sport club activities constantly. Some of the football clubs have a source of funds and participate most of the different football leagues on the local and international level, and these sources will be a strong reason to concentrate on the SM to develop their marketing."

In addition, $\mathrm{P} 9$ had a similar reading on the power of SM as a strong channel and said:

"Yes, we can see the SM as a strong channel for promoting the sports marketing. Recently, many of the sport clubs are adopting the SM in Northern Iraq, thus I am sure that they can learn about the usage of SM completely in the future."

As well as, participants were asked to comment about the SM power to develop the marketing activities of the football sport clubs. P12 replied:

"We can see the SM as a strong channel for developing the sports marketing. In Northern Iraq, the people are taking care about more types of the SM and Zakho football club will have a plan to make another sort of the SM like (Instagram, Viber, and others) and use them to have the ability to serve the sport fans effectively."

Today, the SM platform runs an essential role in enhancing the marketing strategy and White et. al., (2017), explain that SM marketing is a process which has engaged in leveraging social interactivity between consumers in free SM scenes with a quick-paced stream of information, it is recognized as a vital part of interactive marketing communications, therefore many marketers establish the SM into their marketing strategy (White et. al., 2017). Research participants expressed their ideas on how they engage their fans to improve their marketing strategies as: 
"We believe that the SM is playing a major role to develop the marketing strategy of the football clubs in Northern Iraq. Many of the football clubs have recently started using the SM and they need more practice in order to grow their marketing via the SM."

Both of the SM and TM have a difference an important role in developing the sports marketing, according to (Wenner, 1998), the TM as a reliable source for the football sport teams and most of the news or facts which are shown in the TM are correct, even though (Westberg et. al., 2018), say that the practicing of SMP to raise consumption is a forceful channel than the TM due to the improved capability for interactivity, timeliness, targeting and access to consumer networks, and just as the P2 mentioned as below:

"Every time, we can see the SM as a strong situation, but the country of status decides that the SM is a channel to enhance the sports marketing. I bet, it is not only the SM that have made an influence on the sports marketing; but also the TM have made an impact on the sports market, too. Today, in Northern Iraq, we can see the SM as a strong channel for developing the sports marketing, because many of the sport fans now are depending on the SM."

Except this, the P7 expressed the different opinion in comparison to the P2 and he mentioned:

"Yes, surely we can see the SM as a strong channel for developing the sports marketing. In Northern Iraq, using the SM has more benefit than the TM, because the SM doesn't need a lot of money and time. In Northern Iraq, if we want to advertise via the TM, we have to choose some strong TV channels like (Rudaw or $N R T)$, but these channels ask $\$ 100$ for only one second, so that it isn't appropriate for the football clubs of Northern Iraq when they don't have a good financial situation. Therefore, the SM is the only way to get your objectives."

In addition to, the participants replied to the following question that was asked in the thesis by the Interviewer: How the efficient usage of the SM would help the efficiency of the football sport clubs? And they reacted as:

"Surely, the SM would help the efficiency of the football sport clubs, but you have to use this tool on an academic level, it means that the club has to have their official media page and print any ads or information every second. Furthermore, the person who embraces any media page must be a competent person in the field of Net, so that it helps the sport clubs to get the desire of customers and increase their number of fans."

Contrarily, there were a few participants who refused the SM as a strong marketing channel such as the P4 that clarified as below:

"No, we cannot see the SM as a strong channel for developing the sports marketing strategy, because in Northern Iraq many of the sport clubs haven't understood the efficient usage of the SM."

In a similar way, the researcher asked the same question from the P5, can we see the SM as a strong channel for developing the sports marketing? And he replied as follows:

"We can consider many SM tools as a strong channel for recovering the sports marketing, but in IKR the football sport clubs need more time to comprehend the SM as a strong channel for developing the marketing strategy." 


\subsection{Profitability via Social Media to Engage Fans}

The practicing of SM is inexpensive, and Michaelidou et. al., (2011) signed that the SM does not need a strong financial investment, and the pretty low cost is surely a benefit of developing a SM site as a marketing communication tool, especially it provides the opportunity for the football team to reach a huge income from these developments, and also P4 discussed as below:

"All the services and products of the football sport clubs are considered as the club finance because if we make an official media page and understand the power and efficiency of the SM, then the club can take the benefit."

Similarly to P4, P12 confirmed the low-cost SM as:

"...actually, all kinds of advertising through the SM for any purpose represent a power of the club finance level automatically, because doing the marketing by the SM doesn't need so much money and time, so using the SM will result in developing the club finance level."

The football sport clubs can advertise for their source funding through the SM tools, because it will raise the financial level of sport club effectively. According to Neale et. al., (2003), because the SM tools such as Facebook can help the purchase, the game attendance, team ticket owners, and company sponsors who make the most of the profits, and currently, Facebook has developed into the world's highest community of sports fans through giving a platform for 650 million people to join with sports pages, and also it is true that the Facebook has become the world's greatest stadium (Jalonen, 2017), for this reason, the P1 mentioned this as follows:

"The football sport clubs can advertise by practicing the SM and present their services to their fans successfully. Many of the football sport clubs have a source of funding, especially (small football pitches, sports hall, fitness hall, and the others). So, if they can advertise for these sources by the SM tools it empowers the financial situation of the club."

In addition, P6 said:

"We have a small football pitch (six players) that it is hired daily and every time we are doing promotion by the Facebook and this method led to make many customers for this stadium and present more financial gain for the club".

Similar to P9 who stated that:

"We have a small football pitch (six players) which is hired daily and we do the marketing for this pitch through the Facebook or we have a swimming pool that is promoted by the SM constantly. These sources provide the financial gain for the club".

P10 also stated this as:

"My club has an international football stadium and many football pitches (six players) with other possessions. We participate in the Iraq, Asia, and Northern Iraq football leagues yearly, if we can promote for all our properties through the SM it will help us to upsurge the financial club".

Besides, increasing the sport fans via the SM is lucrative as it makes money for the football sport teams, and also the ticket selling has been affected through the SM tool. Westberg et. al. (2018) explains that the sport has embedded in the sociocultural framework 
of a lot of states and invested fans across a wide range of demographic groups, moreover Kim et. al. (2011) say, any time the fans feel that they have a great relationship with a club, it will increase their wishes to buy gear, plus tickets successfully, also P2 mentioned the following method:

"Most of the products or services of the football sport clubs are more profitable via the SM, but I figure, the sports fans are most profitable for the club and every time we try to embrace many fans via the SM. My sport club participates in the Iraq football league and selling the ticket has a good market at this time, thus we have the best benefits for the club."

The most important question of this thesis that some participants could give the exact answer to the interviewer is: Which product or service of the football sport clubs is more profitable via the SM? The P3 could reply to this as follows:

"... Actually, all services or products football sport clubs are profitable, but according to my understanding, in Northern Iraq, promoting for the football game ticket by the SM which is so lucrative for the club.", as well as, P5 involved the similar question and he said, "... Actually, all the products or services of the football sport clubs are more profitable via the SM, but it is a good situation if we can raise the number of the sport fans via the SM because they will be our customers finally."

In the same manner, it was one of the below questions which orientated the participants via the researcher: What are the most important and useful SM tools to increase the relationship between the football sport club and the fans? And all respondents could give the reasonable answer, such as they mentioned:

"If the football clubs use the SM tools, particularly Facebook for increasing the sport fan number, it is a successful approach and they must stick to it, also many of the football sport clubs in Northern Iraq haven't succeeded to increase their number of fans by the SM, but football sport clubs have to depend on more than one type of the SM in order to raise the number of fans successfully"

Results revealed that $15 \%$ of the ticket selling has been affected by Facebook posts. The power of SM tools could enlarge profits from ticket selling. Those who purchase tickets via SM tools pay over 11/2 times in comparison to the conventional purchaser, while P8 referred to it as below:

"When we start the Iraq football league, especially those matches which are conducted in Northern Iraq, it has the most fans, therefore it is a good thing if the football sport club can do promotion for their ticket via the SM (Facebook), it makes the financial advantage for the clubs."

In the same manner, P11 clarified this as:

"There are some football sports clubs in the Northern Iraq which have a small football pitch and the others can hire them monthly so that it is too important if they will make a customer for their stadium by using the SM tools and empower the financial situation of the club. On the other hand, there are some football sport clubs with a lot of fans around Iraq and they have an international stadium, if they can promote to sell their tickets via the SM, it makes the matches important, too." 
Besides, all participants answered the following question that was asked through the researcher: How would you describe the ways in which the football sport teams are currently using via SM? Can you please give us an example of the football sport teams that have been successful in using the SM? Participants' answers were similar to these questions. One of the participant expresses his idea as:

"Actually, in Northern Iraq, these ways that the football clubs are using the SM are not so successful, even though some of the football clubs could understand from the efficiency of SM, but their number is too little. In IKR, there are a few football sport clubs which are too active by using the SM as an advertising tool, but many of them thought that the football sport clubs such as Erbil, Sulaymaniyah, and Zakho are pretty successful."

On the other hand, there was a respondent who expressed his opinion from a different side regarding to the SM as a profitable way for the football clubs, such as P7 that explained:

"The SM is not only a lucrative method for the football clubs but also they have to understand that how it can increase the sport fans for their clubs via the SM, then the clubs can see the SM as a gainful way."

The football sport clubs can adopt the SM to communicate immediately with their fans on club broadcast, promotions, and ticket sales, also (Tang and Cooper, 2017) have concentrated on their analyzing who conducted in November 2017: The sports have the highest SM fan base, especially the football game, as well as there are some games (like table tennis, Judo, and triathlon) which have a poor fan base but enjoy a strong SM presence. Therefore, participants were asked to answer their opinions about the ways the SM has an impact on the advertising of football sport teams and sport clubs ways to you advertise their sports events. Many of the participants replied:

"Every announcement has an impact on the marketing of the football clubs by the $S M$, but if we designate these ads that have an effect on the development of the marketing of the clubs, so any ads which are related to the football game or players are the most effective ones on the clubs." and "The advertisements for our sport events are now running through the local TV, newspaper and magazine, and recently we have focused on the Facebook for posting news)."

Contrarily, there were some opinions from the respondents who didn't agree on the SM as the only strong advertisement tool to promote the activities and they referred to the importance of the traditional media, such as P4 stated this as follows:

"I don't think that only the SM has impacted on the market as an advertisement, so the marketers have to pay attention the traditional media such as (billboard, $T V$, Door-to-door sales and print advertising), in order to make an exact decision on their activities." apart from these views, P9 though: "... embracing the SM as is not a successful way in the Northern Iraq, because many of the football sport clubs have started to use the SM since 2017, and some of them are more focused on the TM, even though the clubs will be successful by using the SM as in the future."

\section{Conclusion, Implications and Limitations}

This aim of this to examine the effectiveness of social media for the football sport club's marketing strategy in Northern Iraq. Based on the results of this study the conclusion that can 
be drawn could contribute to the overall discussion of the role of SM platforms. There is a vital theme that links with using the SM as a strong channel of marketing strategy. Results showed that the SMTs are strong marketing channels because of revealing a lot of important features such as empowering the web users to organize specify all the different information and it is a forceful opportunity for the football sport clubs to develop their marketing strategy, as it is also supported by the relevant literature. SM marketing is a process which has engaged in leveraging social interactivity between consumers in free SM scenes with a quick-paced stream of information. It is recognized as a vital part of interactive marketing communications, therefore many marketers establish the SM into their marketing strategy. Results revealed that, the football sport clubs in Northern Iraq have to adopt the SM as a strong channel for developing the sports marketing strategy, when the financial situation of many football clubs in Northern Iraq is bad, hence the football clubs must implement their objectives via the SM.

Another theme relates to the profitability via the SM to engage fans. Results showed that increasing the number of sport fans is the best outcome for the football clubs, because happy fans through the SM are causing of produce revenue, and the football match tickets selling made influence on the improvement of the marketing clubs where this results is also supported by the relevant literature because the SMTs like Facebook can enlarge the purchasing profits of the football club and hold the game appearance, term ticket owners, as well as enthusiastic sport fans through the SM are lucrative and make money for the football sport teams. Therefore SM tools have become a vital channel for sport teams to interact with fans successfully. Results also revealed that especially for football clubs which have smaller marketing budgets, moreover, the development of SM tools have created a leadership for the football clubs to engage fans, a particularly Facebook tool. For this reason, the football sport clubs should engage the sport fans as a key product, although any product or services through the SM tools, particularly Facebook run a crucial role of improving the financial situation of their clubs. According to Bee and Kahle (2006), the good relationship with the fans through the social media makes an influence on the development of the sports marketing strategy dealings, especially Facebook has recently developed into the world's highest community of sports fans through giving a platform for 650 million people to join with sports pages, and also it is true that Facebook has become the world's greatest stadium (Jalonen, 2017).

There is a vital theme that link with using the social media as a strong channel of marketing. Results showed that the social media tools are strong marketing channels because of revealing a lot of important features such as empowering the web users to organize specify all the different information by the best method and it is a forceful opportunity for the followers and football sport clubs to communicate more with each other, as explained by (Mangold and Faulds, 2009), the social media is a strong channel for boosting the sports marketing and enables customers to discuss with one another or thousands of other people.

One of the arguments supports the adopting of social media tools as a marketing strategy. Results presented that the social media is a powerful way for developing the marketing strategy of the football sport clubs in Northern Iraq and they can make success by embracing these media tools, because practicing the traditional media needs financial resources in Northern Iraq, when the financial situation of many football clubs in Northern Iraq is not good, hence the football clubs can implement their objectives via the social media as a marketing strategy. White et al. (2017), explain that social media marketing is a process which has engaged in leveraging social interactivity between consumers in free social media scenes with a quick-paced stream of information, furthermore the social media tools have granted a new framework of the communication method, it is recognized as a vital part of interactive marketing communications, as well as consumers practice the social media stations to interact with each other or companies, therefore many marketers establish the social media into their marketing strategy, similarly Rothschild, (2011) discovered that there is momentous 
growth in the marketing strategy of the football clubs because they are more concentrated on social media, particularly Facebook to engage the fans for a better advertising method and also more practical communication approaches.

Given the information found from this study, it's vital to highlight the most revealing content and present it for future endeavors relating to the social media, relationship with fans, and football sport clubs. Based on the results of the study, one of the recommendations for football clubs presidents is to recruit talented staff to manage the official media pages in different languages and understand the sports marketing which lead the football clubs to have an expert person to comprehend the efficiency of the social media tools.

In conclusion, this study found that the effectiveness and efficiency of the SM tools, especially (Facebook) are the foremost stations to thrive the sports marketing strategy of the football sport clubs in Northern Iraq in order to increase their relationships with their fans, as well as the football sport clubs should improve their SM networks in a professional way. This study is limited with football sport clubs presidents' participation. For future research football sport clubs funs and government representatives can be included in the sample, thus, data can be generalized to the whole population.

\section{References}

Anderson, D. (2008). Man Utd's 333M fans, Daily Mirror, 8 January, available at: http://www.mirror.co.uk/sport-old/football/2008/01/08/man-utd-s-333m-fans-115875 20278453/. (Accessed on 17 November 2016).

Askool, S., and Nakata, K. (2011). A conceptual model for acceptance of social CRM systems based on a scoping study. AI \& Society, 26(3), 205-220.

Azizi, N. and Tambuan, S. M. G. (2018). Constructing an imagined community of fandom and articulating gender identity: A case study on Indonesian female football fans' participation in social media. Cultural Dynamics in a Globalized World.311-316.

Barker, M. Barker, D., Bormann, N., and Neher, K. (2012). Social Media Marketing: A Strategic Approach. Southwestern College Publishing International edition. New York.

Bayern Munich. (2011). FCB posts profit for 18th year in a row, available at: http://www.fcbayern.telekom.de/ en/news/news/2010/26911.php, (Accessed on 17 November- 2016).

Bee, C. and Kahle, L. (2006). Relationship Marketing in Sports: A Functional Approach. Sport Marketing Quarterly, 15 (1), 102-110.

Berthon, P. R., Pitt, L. F., Plangger, K. and Shapiro, D. (2012). Marketing Meets Web 2.0, Social Media and Creative Consumers: Implication for International Marketing Strategy. Business Horizons, Kelley School of Business, Indiana University, 55(2), 261271.

Blackshaw, L. (2012). Sports marketing agreements: new media. Science Business Media, Springer: Berlin.

Bryman, A. and Bell, E. (2011). Business Research Methods, 3rd Edition. New York, Oxford University Press.

Cass, B. (2007). United is moving down south as a fan base reaches 333 Million, Daily Mail Online, 15 December 2007, available at: http://www.daily mail.couk/sport/football/article-502574/ (Accessed on 15 November 2016).

Chadwick, S., Chanavat, N. and Desborde, M. (2015). Marketing of the sports club. New York: Routledge Handbook of Sports Marketing. UK.

Charness, N. and Holley, P. (2004). The new media and older adults: usable and useful. The American Behavioral Scientist, 48(4), 33-416.

Crowther, P. (2010). Marketing space: A conceptual framework for marketing events. The Marketing Review, 10(4), 369-383. 
Domingo, D. and A. Heinone. (2008). Weblogs and Journalism: A Typology to Explore the Blurring Boundaries. Nordicom Review, 29(1), 3-15.

Eric, C. Schwarz, Jason, D. Hunter, and Lafleur A. (2013). Advanced theory and practice in sport marketing: introduction to sports marketing. New York.

Gadiraju, G. K. (2016). Impact of social media in sports marketing. ISCTE business school, Institute Universitario de Lisboan.

Garrison, B. (2001). Successful Strategies for Computer-Assisted Reporting. Mahwah, NU, USA: Lawrence Erlbum Associates.

Gluck, M. \& Rocam, M. (2008). The future of Television? Advertising, technology and the pursuit of audiences. University of Southern California.

Goodyear, V. A., Casey, A. and Quennerstedt, M. (2018). Social media as a tool for generating sustained and in-depth insights into sport and exercise practitioners' ongoing practices. Qualitative Research in Sport, Exercise and Health, 10(1), 1-6.

Graneheim, U. H., and Lundman, B. (2004). Qualitative content analysis in nursing research: concepts, procedures and measures to achieve trustworthiness. Nurse education today, 24(2), 105-112.

Haynes, R. (1995). The Football Imagination: The Rise of the Football Fanzine Culture. Aldershot: Arena.

Hutchins, B. (2011). The acceleration of media sport culture: Twitter, telepresence and online messaging. Information, Communication \& Society, 14(2), 237-257.

Hutchins, B. \& Rowe, D. (2012). Sport Beyond Television: The internet, digital media and the rise of networked media sport. New York: Rutledge.

Invest in the Group. (2013). Overview: Kurdistan region Telecom (Internet use). http://www.investingroup.org/publications/kurdistan/overview/telecom/. (Accessed on November 20, 20152017).

Jackson, N. (2013). Promoting and Marketing Events: Theory and Practice. Routledge: New York.

Jalonen, H. (2017). Social Media as a 'Service'for Value Co-Creation by Integrating Sponsoring Companies, Sports Entities and Fans. International Journal of Social, Behavioral, Educational, Economic, Business and Industrial Engineering, 11(1), 13-20.

Jarvie, G. (2013). Sport, culture and Society: Social media and sports club. New York.

Joseph, B., Bayer, E. N., Sarita, Y., and Schoenebeck, F. E. (2015). Sharing the Small Moments: Ephemeral Social Interaction on Snap chat. 65th Annual Conference of the International Communication Association.

Kendall, G., Knust, S., Ribeiro, C., and Urrutia, S. (2010). Scheduling in sports: An annotated bibliography. Computers and Operations Research, 37(1), 1-19.

Kim, Y. K., and Trail, G. (2011). A conceptual framework for understanding relationships between sport consumers and sport organizations: A relationship quality approach. Journal of Sport Management, 25(1), 57-69.

Mance, H. (2014). Six things to know about Viber. Financial Times.

Mangold, W. G., and Faulds, D. J. (2009). Social media: The new hybrid element of the promotion mix. Business Horizons, 52(4),357-365.

Manoli, A.E. (2017). Sports marketings past, present and future: an introduction to the special issue on contemporary issues in sports marketing. Journal Strategic Marketing, 26(1), $1-5$.

Mangold, W. and Faulds, D. J., 2009. Social media: The new hybrid elements of the Promotion mix: Design products with talking points and consumers' desired self images in mind. Business Horizons, 52 (1), 357-365.

Manzenreiter, W. (2004). Japanese football and world sports: raising the global game in a local setting, Japan Forum, 16(2), 289-313. 
Michaelidou, N., Siamagka, N. T. and Christodoulides, G. (2011). Usage, barriers and measurement of social media marketing: An exploratory investigation of small and medium B2B brands. Industrial Marketing Management, 40(2), 1153-1159.

Morgan, J., M. and Summers, J. (2005). Sports marketing: what is the sports marketing? Australia.

Musser, O. (2007). Mashing up the once and future Short Message Service (SMS). Educause, 2(42), 8-9.

Neale, L., Georgiu, T., and Purchase, S. (2003). Membership retention within the Sporting industry: factors affecting relationship dissolution. Sharing best Practices in sport marketing: the Sport Marketing Association's inaugural Book of papers. Inaugural Conference, November, 2003-2004. Morgantown: WV, fitness information Technology, 179-194.

Newman, T., Peck, J., Harris, C. and Wilhide, B. (2013). Social Media in Sport Marketing. Scottsdale, AZ: Holcomb Hathaway.

Parent, M., and Smith-Swun. (2013). Managing major sports events: Theory and practice, Relationship between sport and media: on promoting the sound development bilateral relations. New York.

Pritchard, M., and Stinson, J. (2014). Leveraging brands in sport business. New York: Routledge.

Pronschinske, G. M., and Walker, M. (2012). Attracting Facebook Fans: The Importance of Authenticity and Engagement as a Social Networking Strategy for Professional Sport Teams. Sport Marketing Quarterly, 21(4), 221-231.

Rothschild, P.C. (2011). Social media use in sports and entertainment venues. International Journal of Event and Festival Management. 2(2), 139-150.

Saini, D. (2015). Effects of Media on Sports. International Journal of Applied Research, 1(4), 320-323.

Sanderson, J., and Kassing, J. (2011). Tweets and blogs: Transformative, adversarial, and integrative developments in sports media. New York: Routledge., PP. 114-127.

Saw, G., Abbot, W., Donaghey, J., and McDonald, C. (2013). Social Media for International Students: It's Not All About Facebook. Library Management, 34(3), 156-174.

Schwarz, T. (2008). Erfolgeiches online marketing Schrittfur Shirt zum Ziel. Munchen: Haufe,

Shilbury, D., Westerbeek, H., Quick, S., and Funk, D. (2009). Strategic sport marketing: promotion mix (Licensing). Australian.

Sinha, A. (2007). Sweet Spot: How to Maximize Marketing for Business Growth/ Digital marketing vs Traditional marketing. Canada: Hoboken, New Jersey.

Smith, A.C.T. (2008). Introduction to sport marketing: Two angles of sport marketing. Elsevier Ltd, Oxford.

Tang, T., and Cooper, R. (2017). The most social games: Predictors of social media uses during the 2016 Rio Olympics. Communication \& Sport, 6(3), 308-330.

Thompson, J. L. (1997). Strategic management. Awareness and change. International Thomson Business press. London.

Ward, D. (2003). Impact of New Technology on the Traditional Media: Overview the traditional media. London: Lawrence Erlbaum Associates, 2003.

Wenner, L. (1998). Media Sport: The traditional media. London: Rutledge.

Westberg, K., Stavros, C., Smith, A. C. Munro, G., and Argus, K. (2018). An examination of how alcohol brands use sport to engage consumers on social media. Drug and Alcohol Review, 37(1), 28-35.

White, D., White, C., and White, D. (2017). Sponsorship-Linked Marketing: Using Social Media Brand Affinity Data to Determine Sort Sponsorship Effectiveness. Sports Marketing. 369-370. 
Williams, J. (2006). 'Protect Me from What I Want: 'Football Fandom, Celebrity Cultures and 'New' Football in England. Soccer and Society, 7(1), 96-114.

Williams, J., and Chinn, S.J. (2010). Meeting relationship-marketing goals through social media: A conceptual model for sport marketers. International Journal of Sports Communication, 3(2), 422-437.

Witkemper, C., Lim, C., and Waldburger, A. (2012). Social Media and Sports Marketing: Examining the Motivations and Constraints of Twitter Users. Sports Marketing Quarterly, 21(2), 170-183.

Yildirim, A., and Simsek, H. (2006). Sosyal Bilimlerde Nitel Araştırma Yöntemleri [Qualitative Research Methods in Social Sciences], 5th ED. Seckin Yayıncılık, Ankara.

\section{Author Biography}

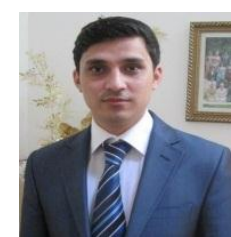

Azhi Khalil Bapir is a DBA student in Business Administration at the Cyprus International University.

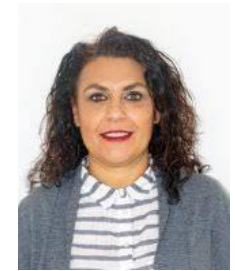

Hale Ozgit is currently an Associate Professor at the School of Tourism and Hotel Management at Cyprus International University, School of Tourism and Hotel Management. Her Ph.D. focused on the evaluation of tourism education in higher education from strategic management perspective. Her research interests are tourism, tourism education, organizational behavior, and human resources management. 